\title{
Designing an Ardunio-microprocessor-and- Labview-based system for monitoring wave spread in the ground caused by constructing activities
}

\author{
Nguyen Lan ${ }^{*}$, Chau Ngoc Bao ${ }^{2}$ \\ ${ }^{1}$ The University of Danang- University of Science and Technology \\ ${ }^{2}$ Center for Science and Technology and Investement Consultancy- DUT.
}

\begin{abstract}
There are many activities such as embankment vibratory rollers, piling, blasting tunnel ... causing wave spread in the ground that affect the surrounding buildings. The high ground wave may damage the surrounding buildings and hence may cause confrontations between the local resident community and the project owners. To determine the radius of vibration of each vibrating source that can damage the neighbouring buildings as the basis for planning, choosing construction technology, and designing damping methods to minimize the risk to the surrounding buildings, It is necessary to measure experimental vibration in the field. This paper describes how to install the Ardunio-circuit-based vibration measuring system ; by using labview and shows some experimental results of measuring vibration transmitted to the ground caused by constructing activities in Da Nang, Vietnam. The results prove that the measuring system has a considerably low cost and meets the standards and precision according to Vietnamese ISO 7378 and DIN 4054. The software written on Labview platform is connected to the hardware to collect vibration signals from sensors, analyse measurement data, and then make reports on measurement results in table or chart formats to meet the current standard vibration measuring requirements.
\end{abstract}

\section{Overview of the wave propagation in the soil due to construction activities}

The principal wave types that transmit vibratory energy away from a source on or near the ground to a distant receiver include Rayleigh (R-) waves; Shear (S-) waves; Compression (P-) waves. Essentially, these three main wave types can be divided into two categories: body waves, which propagate through the body of the soil; and surface waves, which are transmitted along a surface (usually the upper ground surface) [1].

\footnotetext{
* Nguyen Lan: nlan@dut.udn.vn
} 
The three wave types produce radically different patterns of motion in soil and rock particles as they pass. Therefore, structures will be deformed differently by each type of wave.

The P-, S- and R- waves travel at different speeds. The P-wave is the fastest, followed by the S-wave, and then the R-wave. Along the surface of the ground, the P- and Swaves decay more rapidly than the $\mathrm{R}$-wave. Therefore, the $\mathrm{R}$-wave is the most significant disturbance along the surface of the ground. The R-waves account for $67 \%$ of the total energy, S- waves $26 \%$ and $\mathrm{P}$-waves $7 \%$ when the exciting force is applied vertically to the propagation direction [2]. Several empirical equations have been proposed that describe vibration attenuation through soil for specific cases. The scaled distance approach, presented as equation (1), is commonly used for blasting and pile driving operations [3].

$$
\mathrm{V}=\mathrm{k}\left(\frac{\mathrm{R}}{\sqrt{\mathrm{W}}}\right)^{-\mathrm{n}}
$$

where: V - PPV at distance R from the source;

$\mathrm{W}$ is the energy of source or rated energy of impact hammer;

$\mathrm{k}$ and $\mathrm{n}$ are parameters found by plotting $\mathrm{V}$ versus $\mathrm{R}$ on a log-log plot.

Wiss (1981) [4] notes that $\mathrm{k}$ and $\mathrm{n}$ are unique for each source and soil type combination and this approach cannot be used without detailed site-specific measurements.

Human perception and response to ground vibration varies widely. It depends on individual sensitivity, the frequency, PPV, duration, and on whether or not the event is expected and if so, whether the vibration is expected to cause damage. There are many standards already setting the limits for the vibration which do not affect humans, such as BS 6472-1: 2008 or QCQG 27: 2010 / BTNMT.

Table 1. The maximum value allowed for the vibration acceleration for construction activities (QCQG 27: 2010 / BTNMT) [9].

\begin{tabular}{|c|c|c|c|}
\hline No. & Area & Time in the day & $\begin{array}{l}\text { The level of } \\
\text { allowable vibration }\end{array}$ \\
\hline \multirow{2}{*}{1} & \multirow{2}{*}{ Special area } & 6:00 AM -6:00 PM & $75 \mathrm{~dB}$ \\
\hline & & 6:00 PM - 06:00 AM & base level \\
\hline \multirow{2}{*}{2} & \multirow{2}{*}{ Normal area } & 06:00 AM - 9:00 PM & $75 \mathrm{~dB}$ \\
\hline & & 9:00 PM - 06:00 AM & base level \\
\hline
\end{tabular}

Several countries have adopted standards for evaluating the effect of vibration on buildings. A review of international standards identified the following as being the most suitable for providing guidance as to possible building damage from mechanized construction activity:

$\checkmark$ German Standard DIN 4150-3:1999 Structural vibration - part 3: Effects of vibration on structures;

$\checkmark \quad$ British Standard BS 7385-2:1993 Evaluation and measurement for vibration in buildings, part 2. Guide to damage levels from ground-borne vibration;

$\checkmark$ Swiss Standard VSS-SN640-312a:1992 Effects of vibration on construction. 
Table 2. Vibration guidelines from DIN 4150-3:1999 for assessing effects of vibrations on buildings [6]

\begin{tabular}{|c|c|c|c|c|c|c|}
\hline \multirow[t]{4}{*}{ Type of structure } & & \multicolumn{5}{|c|}{ Vibration thresholds for structural damage, PPV $(\mathrm{mm} / \mathrm{s})$} \\
\hline & \multicolumn{5}{|c|}{ Short term } & \multirow{2}{*}{$\begin{array}{l}\text { Long term } \\
\text { Uppermost } \\
\text { floor } \\
\end{array}$} \\
\hline & \multicolumn{4}{|c|}{ At foundation } & $\begin{array}{l}\text { Uppermost } \\
\text { floor }\end{array}$ & \\
\hline & 0 to & $0 \mathrm{~Hz}$ & 10 to $50 \mathrm{~Hz}$ & 50 to $100 \mathrm{~Hz}$ & $\begin{array}{c}\text { All } \\
\text { frequencies }\end{array}$ & $\begin{array}{c}\text { All } \\
\text { frequencies }\end{array}$ \\
\hline Commercial/indus & strial & 20 & 20 to 40 & 40 to 50 & 40 & 10 \\
\hline Residential & & 5 & 5 to 15 & 15 to 20 & 15 & 5 \\
\hline Sensitive/histor & & 3 & 3 to 8 & 8 to 10 & 8 & 2.5 \\
\hline
\end{tabular}

Note: When a range of velocities is given, the limit increases linearly over the frequency range.

To support measuring and evaluating the spread of wave in the ground caused by constructing activities so that it is possible to minimize the risk to neighboring buildings, this study designed a low-cost Ardunio-circuit-based vibration measuring system as well wrote a software to collect data and analyze vibration measuring figures. The system has been tested and measured for a number of real projects in the recent periods of time.

\section{Designing the system for monitoring ground wave propagation}

To design a ground wave propagation system due to the construction work required by TCVN 7378[10] and DIN 4150 [6] and low cost, we use the following hardware: Ardunio circuit and geophone sensor. The LabVIEW environment is used to write a software to connect the sensor to Ardunio and computer, collect vibration signals, and analyse the vibration signals measured. The system block diagram is shown in Figure 1.

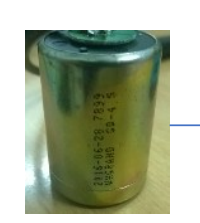

Geophone sensors

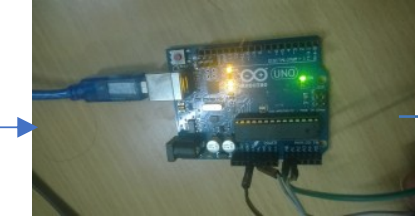

Ardunio

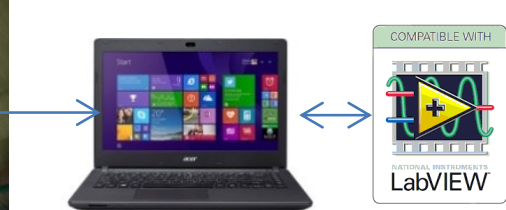

Computer

Labview program

Figure 1. System block diagram for monitoring ground wave pıupayauuı

Graphic User Interface of software for collecting and analysing ground vibration signals in figure 2 . 


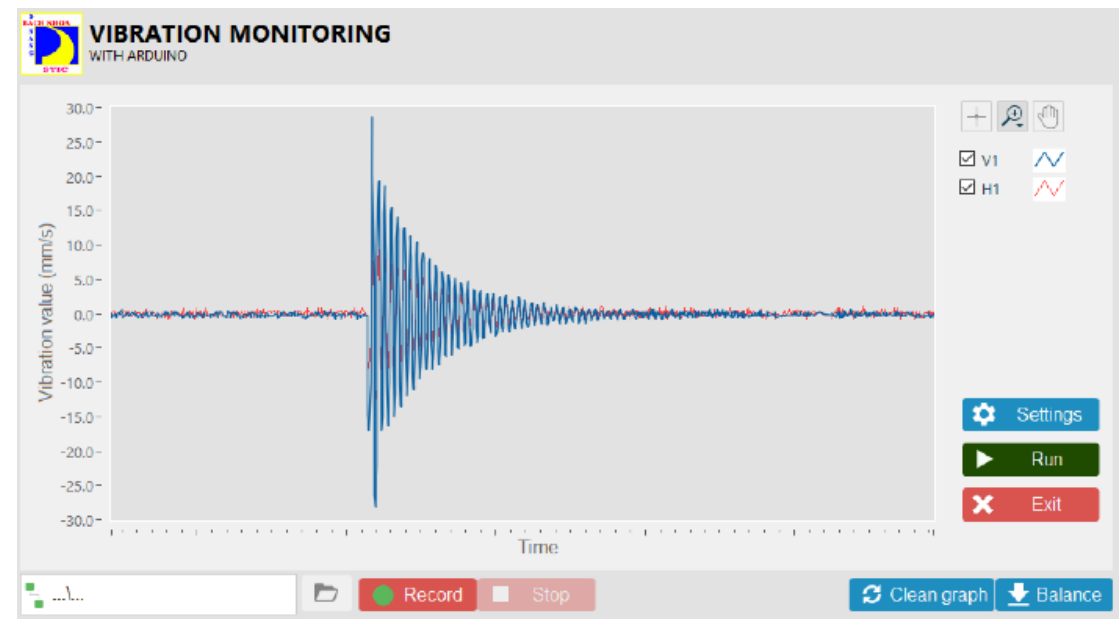

Figure 2. Graphic User Interface of software

Test results of the design system compared with the GPx2 Accelerometer system (USA) on cantilever beam model (Figure 3) show that the free frequency of two systems are similar $(10.5 \mathrm{~Hz}$ and $11 \mathrm{~Hz})$.
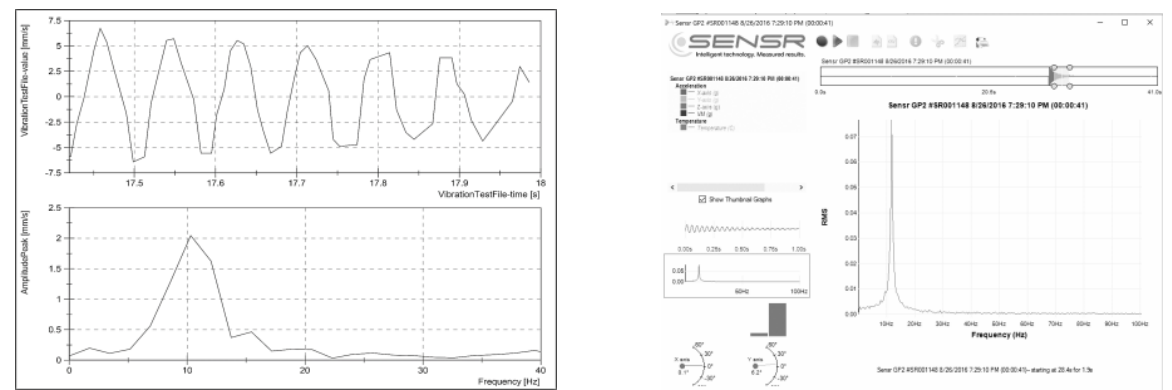

Figure 3. Results of free frequency of cantilever beam model on two systems.

The Arduino circuit cost is about $\$ 20$ compared to other professional dataloggers which cost from $\$ 500$ upwards.

\section{Some results of vibration effective radius due to construction activities}

Summary results of vibration measurements and determination of the radius affect on the surrounding buildings due to some construction activities in reality are given show in Table 3 [5]. 


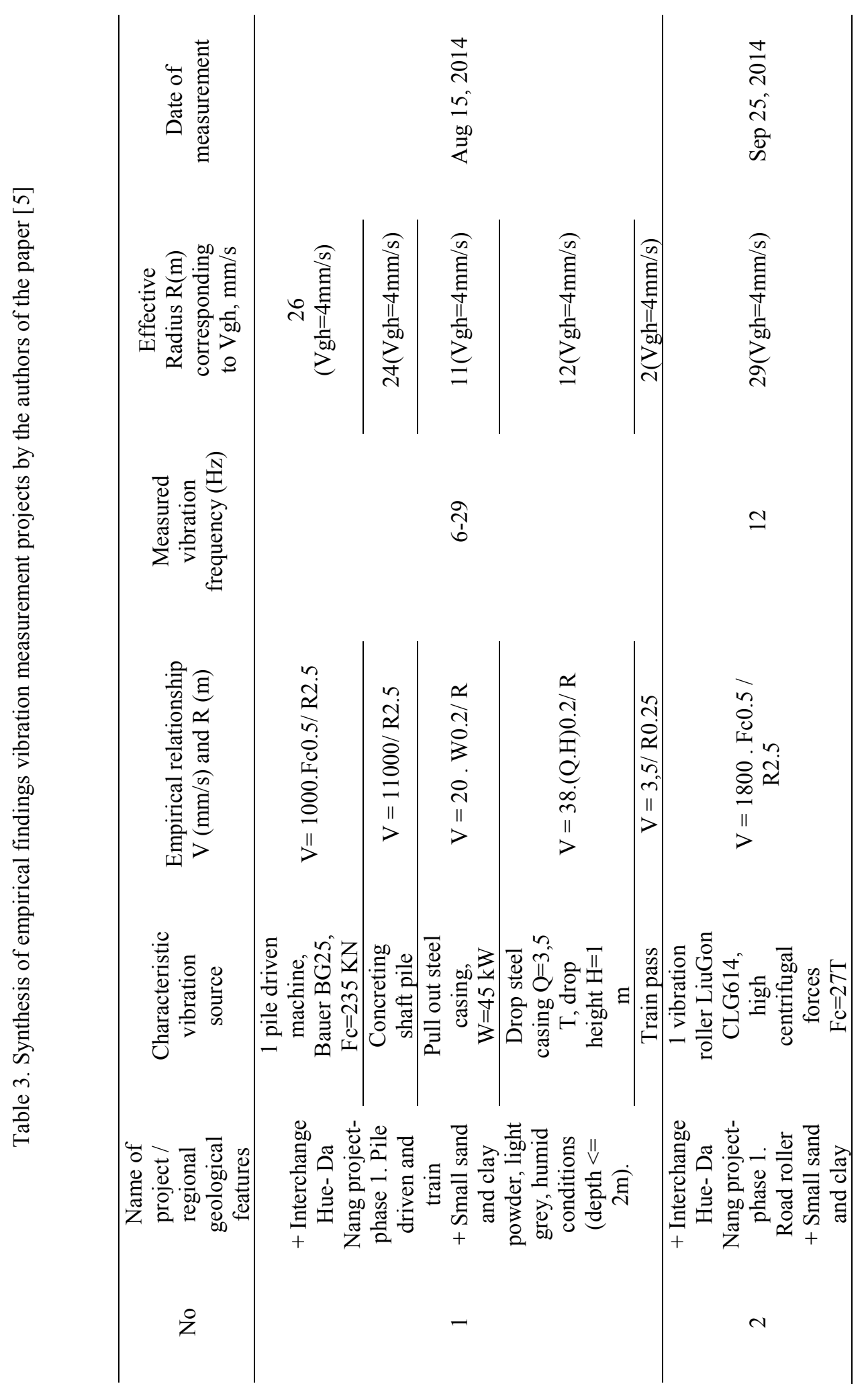




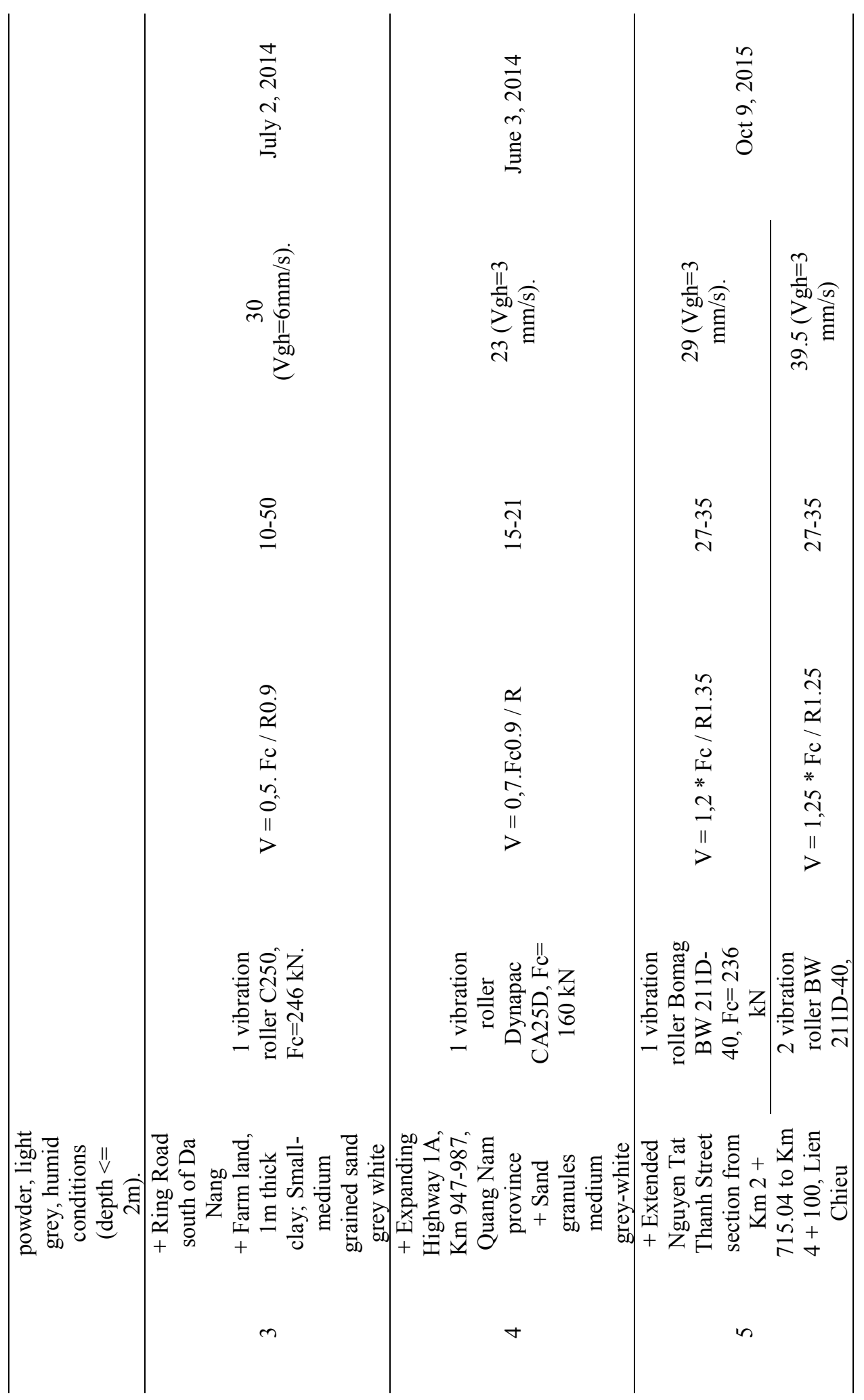




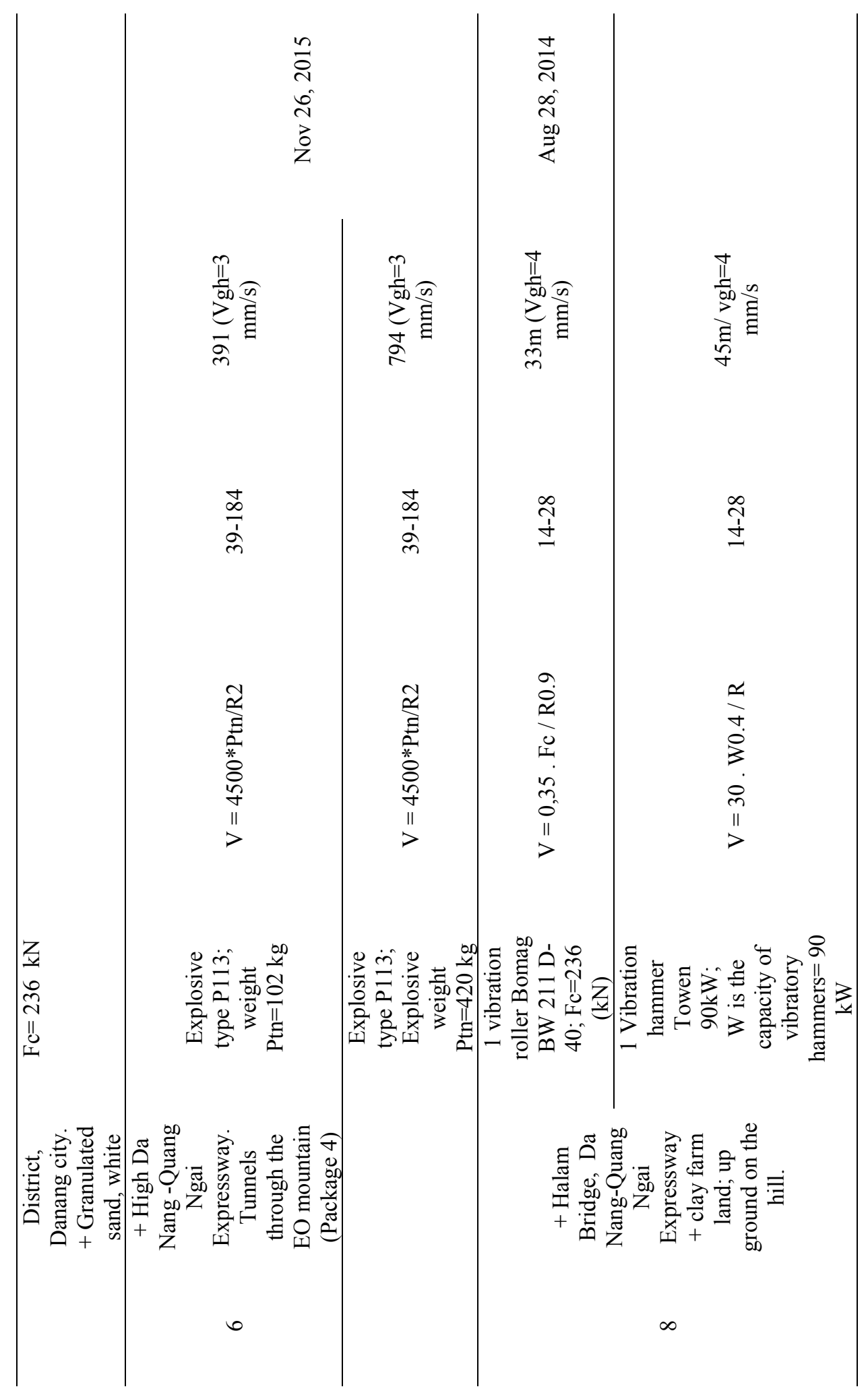




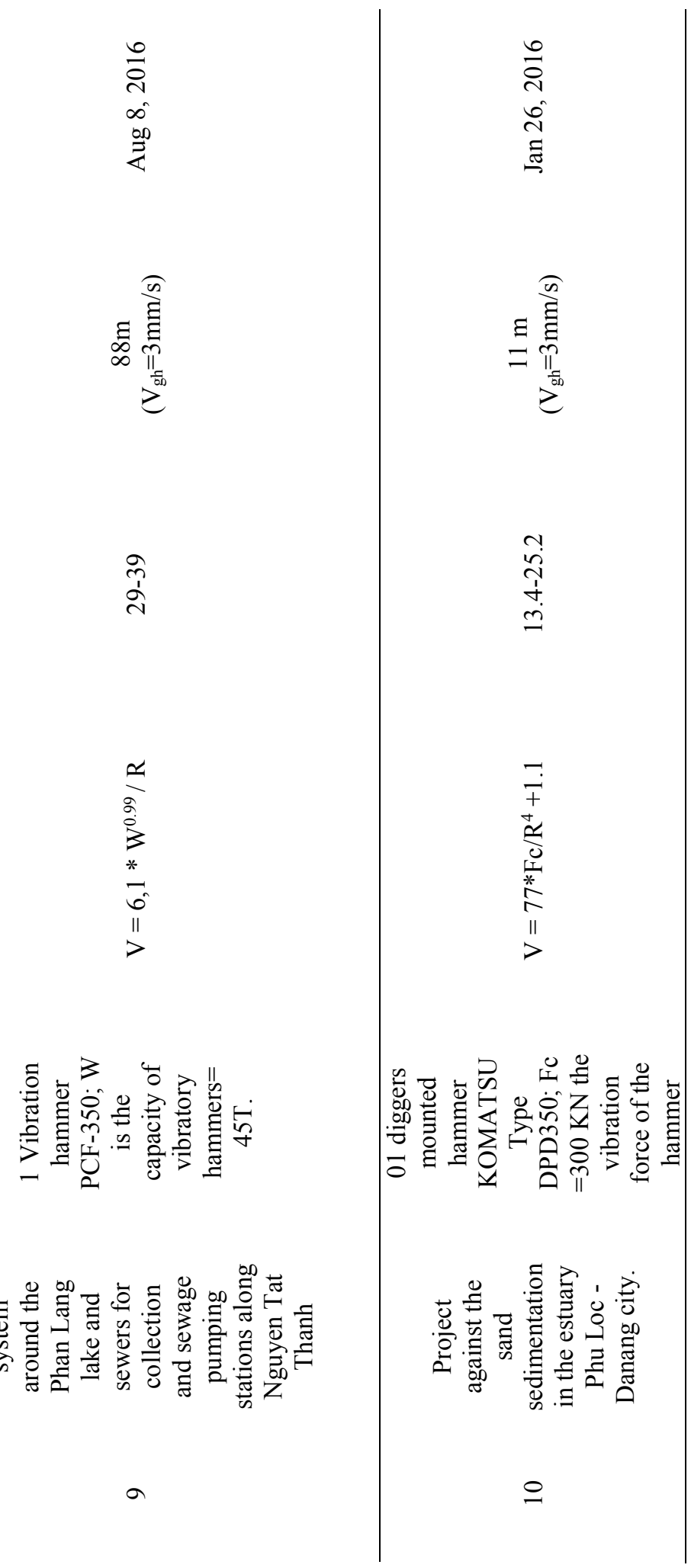


Note: V $(\mathrm{mm} / \mathrm{s})=$ PPVs (Peak Particle Velocity) of ground; $\mathrm{R}(\mathrm{m})=$ adversely affect Radius to neighbouring buildings from the vibration source; $\operatorname{Vgh}(\mathrm{mm} / \mathrm{s})=$ Vibration velocity limits to protect adjacent buildings.

Table 3 shows the radius of influence due to vibration of various construction equipment; it does not only depend on sources of vibration characteristics but also on regional geology conditions.

\section{Conclusions}

Measurement systems for ground vibration monitoring activities due to construction based on vibration velocity sensor (geophone) and ardunio circuit connected to specialized software built on the platform language labview meet the system requirements of a vibration measuring equipment such as TCVN 7378 or DIN 4150-3. Precision of designed vibration measurement system is equivalent to the imported vibration measurement system as GPX (SENRS-USA) but the cost is smaller.

The application vibration measurement system designed to application possibilities of the system design are very good. The measured data from actual projects can be used to predict the radius of influence of vibration sources from construction activities on neighbouring buildings.

The system can be extended to a wide variety of other sensors for measuring purposes and health monitoring of different structures.

\section{References}

1. New Zealand Transport Agency research report 485. Ground vibration from road construction, May 2012.

2. Richart, FE, JR Hall and RD Woods. Vibrations of soils and foundations (Englewood Cliffs, New Jersey, Prentice-Hall,1970).

3. Svinkin, MR, Prediction and calculation of construction vibrations (Proceedings 29th Annual Members Conference Deep Foundations Institute, Dearborn MI: 1-22, 1999).

4. Wiss, JF, Construction vibrations: state-of-the-art. Journal of the Geotechnical Engineering Division ( Proceedings of the American Society of Civil Engineers 107, no. GT2, 1981).

5. Center for Science and Technology and Investment Consultancy- the University of Danang. The vibration test reports of projects, 2014-2016.

6. DIN 4150-3, Structural vibration part 3: effects of vibration on structures, (Berlin, Deutches Institut fur Normung, 1999).

7. BS 6472-1, Guide to evaluation of human exposure to vibration in buildings part1:vibration sources other than blasting (British Standards Institution, 2008).

8. VSS-SN640-312a, Effects of vibration on construction (Zurich, Swiss Consultants for Road Construction Association, 1992).

9. QCVN 27/BTNMT, National Technical Regulation on Vibration (2010).

10. TCVN 7378, Vibration and shock - Vibration of buildings - Limits of vibration levels and method for evaluation (2004). 